\title{
A LITERATURA INFANTO-JUVENIL TRADUZIDA, O TEXTO NÃO VERBAL E A PURIFICAÇÃO
}

Elisângela Liberatti é doutoranda do programa de Pós-Graduação em Estudos da Tradução, da Universidade Federal de Santa Catarina, mestre pelo programa de Pós-Graduação em Estudos da Tradução, da Universidade Federal de Santa Catarina, e tradutora. E-mail: elisliberatti@ hotmail.com

\begin{abstract}
Resumo
O objetivo do artigo é comentar duas limitações concernentes à literatura infanto-juvenil traduzida: o texto não verbal e a purificação, trazendo exemplos e análises pertinentes ao enfoque do trabalho.
\end{abstract}

\begin{abstract}
The objective of the paper is to comment on two constraints concerning translated children's literature: non-verbal texts and purification, bringing relevant examples and analyses to the focus of the work.
\end{abstract}

\section{1) Considerações iniciais}

A literatura infanto-juvenil (LIJ) é uma área de estudo marginalizada e ainda muito pouco explorada nos cenários nacional e internacional. Sobre isso, Shavit (1994) expõe que

No mundo acadêmico atual, a pesquisa em literatura infanto-juvenil não é realmente legitimada, não é muito respeitada, e, se for ao menos tolerada, é vista como um campo periférico e insignificante de pesquisa. Em suma, a pesquisa em literatura infantojuvenil sofre hoje de um status inferior. E se nada for feito sobre isso, tal situação continuará nos próximos anos (SHAVIT, 1994, p. 4, tradução nossa').

Os conceitos sobre o que vem a ser LIJ são diversos e às vezes não consensuais, e com eles os autores buscam definir a nomenclatura mais adequada ao gênero, quem é o público e a faixa etária que se pretende atingir com essa literatura, acompanhada de suas características inerentes.

Tanto a produção de LIJ quanto sua tradução passam por limitações não menos problemáticas se comparadas a outros gêneros literários. $O$ tradutor de qualquer gênero textual deve ter excelente conhecimento das línguas envolvidas na tradução, bom manuseio da linguagem, conhecimento das culturas envolvidas, criatividade, etc. Porém, quando se trata de tradução de LIJ, os problemas de tradução podem ser ainda mais acentuados (KLINGBERG, 1986). Alguns desses problemas são expostos neste artigo e podem ser encontrados em Klingberg (1986).

Dentro desse contexto de pouco reconhecimento de uma área de estudo não menos legítima do que a literatura adulta (LA), o principal objetivo deste artigo é 
contribuir para o aumento de espaço e reconhecimento da tradução de LIJ, comentando características concernentes à LIJ e algumas de suas limitações, além de trazer trechos de duas histórias em quadrinhos da Turma da Mônica como exemplos para ilustrar as limitações abordadas.

Espera-se que este artigo possa ajudar a LIJ a sair de seu posicionamento periférico e alocá-la em sua merecida posição de reconhecimento, bem como contribuir para o campo disciplinar dos Estudos da Tradução, dentro do gênero LIJ.

\section{2) Literatura infanto-juvenil: algumas definições}

Como supracitado, a LIJ é um fértil terreno de pesquisa que tem buscado seu merecido espaço acadêmico. Definições diversas não faltam para tentar abranger os públicos a que se destina essa literatura e o conteúdo de seu texto. Com isso, trago para esta seção definiçõos de LIJ citadas por estudiosos da área, bem como esclarecimentos sobre quais critérios são usados para enquadrar um texto como LIJ.

Segundo Fernandes, LIJ é definida como "um gênero escrito e publicado, se não exclusivamente para crianças, então pelo menos as levando em consideração, incluindo o romance 'juvenil' - que é voltado para os leitores jovens e os adolescentes mais velhos” (FERNANDES, 2004, p. 5, tradução e grifos nossosii). Aqui, Fernandes (2004) vê a criança e o jovem como os receptores centrais das obras de LIJ, as quais devem ser pensadas, escritas e traduzidas tendo a criança e o jovem como seus principais leitores.

Outra estudiosa, Oittinen, vê a “... literatura infanto-juvenil como literatura lida silenciosamente pela criança e em voz alta para a criança” (2000, p. 2). Já Meireles (1984) afirma que as definições de LIJ podem ser divididas em quatro casos situacionais:

1) textos de tradições orais (fábulas e contos de fadas): inicialmente direcionados para adultos em meados do século XVII, foram posteriormente compilados por escritores e dedicados ao público infantil;

2) obras inicialmente produzidas para crianças, mas que após um tempo passaram a ser de uso comum (ex: As Aventuras de Telêmaco, de Fénelon);

3) obras que, originalmente, não foram escritas para crianças, mas que, com o passar do tempo, se tornaram alvo de leitura para esse público, sendo adaptadas ou reduzidas (ex: As Aventuras de Robson Crusoé, de Daniel Defoe);

4) livros escritos especialmente para crianças, cujo objetivo era entreter, transmitir noções morais e apresentar temas apropriados às respectivas faixas etárias. 
Além da divisão de Meireles (1984), Shavit (1999) propõe uma quinta categoria: as obras que são escritas para ambos os públicos, o adulto e o infantil. Nesse caso, o autor dirige-se tanto à criança quanto ao adulto, por meio da temática e da estrutura, agradando, desta forma, a ambos.

Nelly Coelho traz uma distinção entre LIJ e LA, dizendo que o que vai definir se uma obra é considerada infanto-juvenil ou adulta é para quem tal obra foi escrita, ou seja, o público receptor da obra. Ela explica que "em essência, sua natureza [a da literatura infanto-juvenil] é a mesma que se destina aos adultos. As diferenças que a singularizam são determinadas pela natureza do seu leitor/receptor: a criança" (COELHO, 2000, p. 29).

Partindo-se da concepção de LIJ e de LA de Coelho, entende-se que essas literaturas possuem conteúdos semelhantes, porém, a LA é direcionada para adultos e a LIJ para a criança e o jovem, o que significa que, apesar de a LIJ primar pelo uso de linguagem mais simples, não deve ocorrer a redução artística nessas obras. De acordo com Cunha (2006, p.70), "a obra literária para crianças é essencialmente a mesma obra de arte para o adulto. Difere apenas na complexidade de concepção: a obra será mais simples em seus recursos, mas não menos valiosa".

Após breve exposição do que vem a ser a literatura infanto-juvenil sob diferentes enfoques e olhares, passo, então, a discutir a tradução desse gênero textual e as implicações de se traduzir tal gênero.

\section{3) A tradução da literatura infanto-juvenil}

Da mesma forma que a LIJ é uma área de estudo pouco explorada academicamente, a tradução de LIJ também não tem tido espaço devidamente reconhecido na comunidade científica. A falta de interesse na pesquisa científica em LIJ, aliada à juventude do campo disciplinar Estudos da Tradução, acarreta poucos estudos na interface entre LIJ e Estudos da Tradução (LIJ traduzida).Porém, a tradução de LIJ não é de caráter inferior à tradução da LA, e, se necessário, a LIJ passará por ajustes a fim de se adaptar o conteúdo da obra original aos conhecimentos linguístico e cultural da criança e do jovem, além de uma adaptação do que seria apropriado ou não para uma faixa etária de determinada cultura (questões de censura), conforme afirma Puurtinen:

A literatura infanto-juvenil geralmente é vista como um objeto de estudo periférico e não interessante apesar de seu papel multifacetado como instrumento educacional, social e ideológico. Além de oferecer entretenimento e ser uma ferramenta para o desenvolvimento das habilidades de leitura das crianças, ela também é um importante veículo de conhecimento de mundo, ideias, valores e comportamento aceitável. [...] Quando livros infanto-juvenis são traduzidos, talvez seja necessário fazer vários ajustes com intuito de aderir às noções do que é bom e apropriado para crianças, assim como o 
que é considerado de nível apropriado de dificuldade em determinada cultura alvo (PUURTINEN, 1995, p. 2, tradução nossa ${ }^{\text {iiii }}$.

A LIJ, por se enquadrar como literatura de periferia no polissistema literário ${ }^{\text {iv }}$ (EVEN-ZOHAR, 1978), permite ao seu tradutor maior liberdade de manipulação textual, desde que o mesmo obedeça a duas regras, de acordo com LATHEY (2006a):

i. O texto alvo (TA) deve estar de acordo com as convenções culturais do que é aceitável ou não para determinada faixa etária, contribuindo para o desenvolvimento dos valores morais dos leitores;

ii. Deve haver um ajuste do enredo, da caracterização e da linguagem textual a fim de se alcançar as habilidades de leitura e compreensão da criança $^{\mathrm{v}}$.

No Brasil, segundo o jornal $O$ Globo (apud BARBOSA, 2005), para cada livro nacional de LIJ há três livros estrangeiros de LIJ. Isso significa que para cada obra original em português de LIJ, temos três obras traduzidas. Tal cenário já deveria ser suficiente para que mais estudos acadêmicos fossem realizados no que concerne à tradução de obras destinadas a crianças e jovens brasileiros. Além disso, a tradução de LIJ é de vital importância para seus leitores, uma vez que traduzi-la significa disponibilizar mais literatura para seus jovens leitores, aproximando-os de culturas outrora desconhecidas ou distantes de seus mundos. Devido à deficiência de estudos nessa interface, acredita-se, erroneamente, que, por ser de fácil leitura e com estrutura simples, a LIJ seja uma literatura fácil de traduzir. Neste artigo, pretendo, mesmo que brevemente, refutar essa crença.

\section{4) Limitações na tradução de LIJ}

Nesta seção, discuto duas limitações relevantes e frequentes no que concerne à tradução de LIJ: a presença do texto não verbal nesse gênero textual e o processo de purificação pelo qual os textos normalmente passam.

\section{1) A questão do texto não verbal}

Por se destinar ao público infanto-juvenil, a LIJ normalmente conta com a presença de textos não verbais (imagens) com maior frequência do que as obras de LA. O texto não verbal desempenha um importante papel na obra de LIJ, uma vez que atrai e prende a atenção do leitor. As imagens presentes na obra fazem referência ao texto verbal ou o complementam, ou seja, os textos verbal e não verbal não se contradizem, sendo que há uma forte influência das imagens no texto verbal. 
No que tange à tradução, tal cenário não é diferente: a linguagem não verbal também tem papel crucial no texto traduzido. As imagens trazem à tradução de LIJ mais um desafio, devido ao fato de que, na maioria dos casos, imagens e figuras não são traduzidas, por questões editoriais (de tempo e dinheiro). Com isso, cores, figuras ligadas à mitologia e a crenças populares, símbolos, formato de balões para expressar as falas ou pensamentos, etc. normalmente não são reeditados no texto alvo (TA), podendo causar falhas na interpretação de uma dada cultura.

Um exemplo é o significado diferente de balões semelhantes em culturas diversas. A mesma convenção gráfica pode ter diferentes significados em diferentes culturas, i.e., o formato do balão, por exemplo, pode representar algo diverso em outra cultura, o que pode acarretar a falha de compreensão do real significado do balão por parte dos leitores em geral. Isso pode causar equívoco na transmissão da intenção do

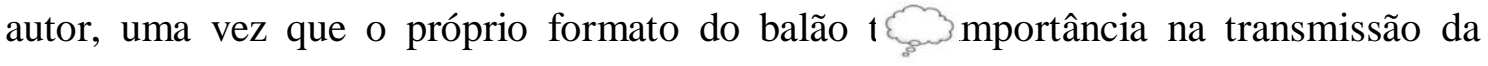
mensagem. Por exemplo, o balão possui sentidos diferentes nas culturas ocidental e oriental, representando pensamento na primeira e sussurro na segunda:

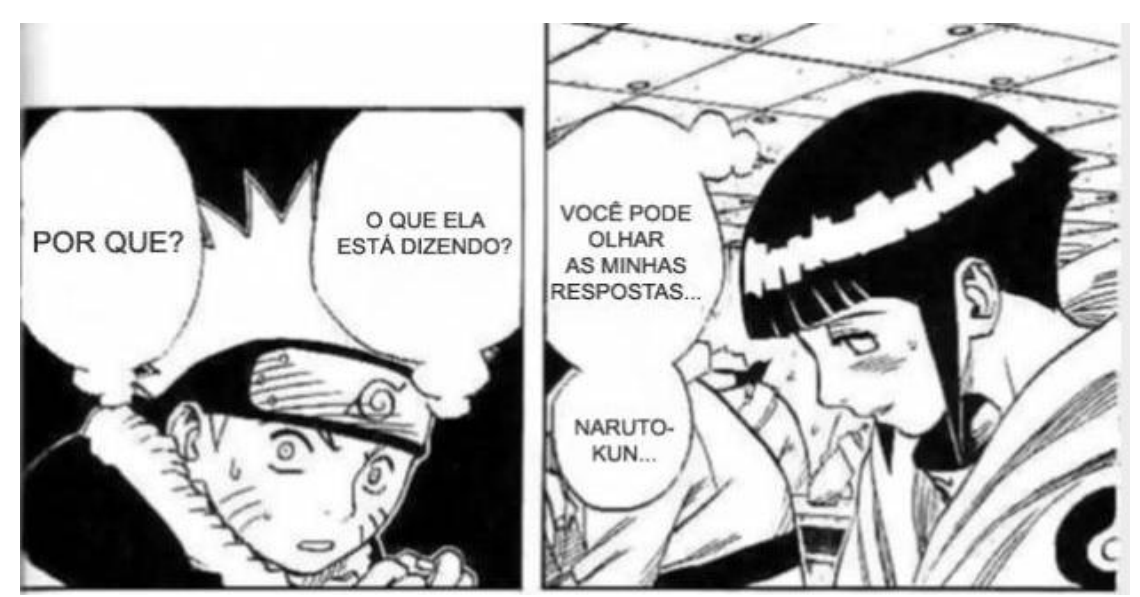

Figura 1: balão do sussurro em quadrinhos orientais 
Já o balão que representa pensamento na cultura oriental é o seguinte:

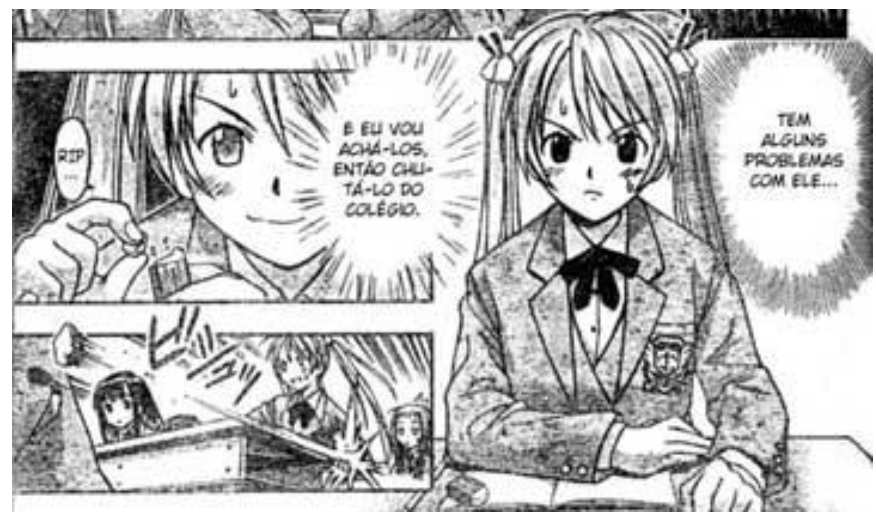

Figura 1: balão do pensamento em quadrinhos orientais

Como já citado, a LIJ pode contar com a presença de imagens, que podem trazer desafios à tradução. Com isso, o gênero quadrinhos traz desafios tradutórios, uma vez que conta, necessariamente, com a presença do texto não verbal, que não possui significado universal:

A crença de que exista um tipo de Esperanto visual baseia-se no pressuposto de que, diferentemente dos arbitrários signos linguísticos, imagens apresentam uma similaridade direta à realidade que representam. No entanto, Eco (1972:202) [...] demonstrou que imagens possuem um código que é governado por convenções, e essas convenções podem ser moldadas por limitações culturais. Isso também significa que as representações visuais de objetos, gestos, expressões faciais, etc. somente podem ser interpretadas corretamente se o significado desses elementos foi definido na cultura em particular (cf. Eco1987:65) (KAINDL, 2004, in VENTOLA et al., p. 183, 2004, tradução nossa ${ }^{\text {vi }}$.

As histórias em quadrinhos (HQs) podem ser destinadas a diferentes públicos, não necessariamente pertencendo ao gênero LIJ. De acordo com Vergueiro (2009), coordenador do Núcleo de Pesquisas de História em Quadrinhos da Escola de Comunicação e Artes da Universidade de São Paulo - ECA/USP, as HQs podem segmentar-se, tendo públicos-alvo diversos: quadrinhos escritos para crianças em geral, para meninas adolescentes, para meninos mais velhos, para adultos, e assim por diante.

No Brasil, são os jovens entre treze e vinte e cinco anos que mais leem HQs. As crianças brasileiras também se dedicam à leitura, mas não de uma forma intensiva e regular. Com isso, nota-se que as HQs em geral têm como principais públicos-alvo crianças e jovens, como afirma Vergueiro:

As crianças naturalmente gostam dos quadrinhos, se identificam com a narrativa. Afinal, a linguagem dos quadrinhos se aproxima muito do universo das crianças e também dos adolescentes. Felizmente, aqui no Brasil, temos uma forte produção infantil 
[basicamente assinada por Maurício de Sousa] que está facilmente disponível no mercado e ao alcance de boa parte dos leitores. A leitura é fácil e prazerosa. Se compararmos com a de outros países, a produção de quadrinho infantil brasileiro é bastante significativa. Nos EUA, por exemplo, não se publica mais quadrinho infantil. Lá, as histórias são voltadas para os jovens (VERGEUIRO, 2009, n.p.).

Partindo para o material de análise, o exemplo trazido para se ilustrar a questão do texto não verbal na literatura infanto-juvenil e suas implicações para a tradução são trechos de uma história em quadrinhos (HQ) do Chico Bento, produzida pela Maurício de Sousa Produções (MSP) em 2005, intitulada Halloween na Roça. Observe os dois quadros abaixo:
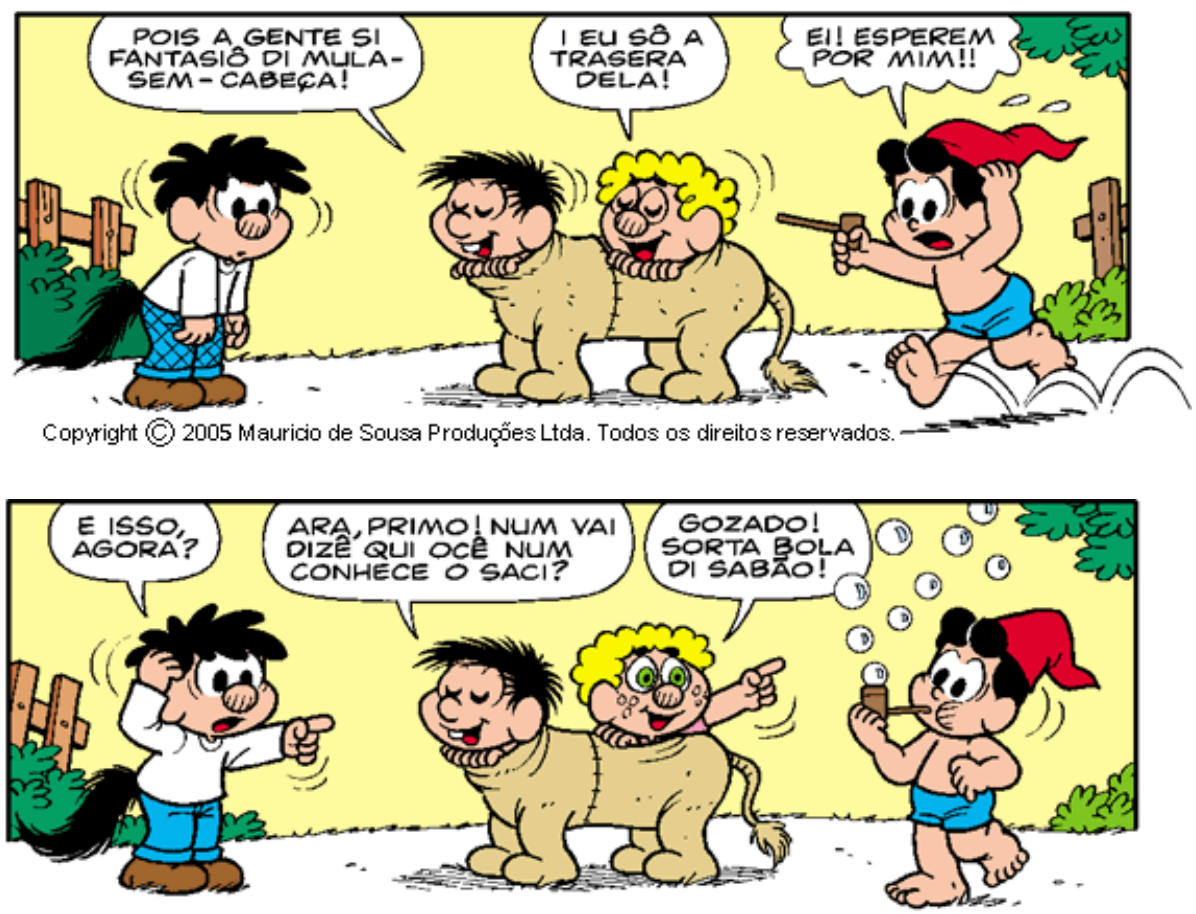

Copyright (C) 2005 Mauricio de Sousa Produçốes Ltda. Todos os direitos reservados.

Ao se observar os quadros acima, a pergunta que se faz é: como se daria a tradução desses quadros para uma outra cultura, se a mula sem cabeça e o saci-pererê são personagens do folclore brasileiro? Como atingir o entendimento do leitor em relação à vestimenta dos personagens e em relação ao que elas representam? Essas são questões complicadas pelo fato de não termos apenas o texto verbal, que é transposto na tradução, mas sim o texto verbal trabalhando em conjunto com o texto não verbal (ou seja, as imagens), que muitas vezes não é redesenhado na tradução por questões editoriais, conforme já mencionado. Com isso, a adaptação cultural que poderia ser feita, para que o leitor pudesse ter uma boa compreensão do TA, fica limitada devido às figuras, que não devem ser contrárias ao texto verbal ${ }^{\text {vii }}$. Ou seja, o texto verbal fica condicionado às figuras. $\mathrm{O}$ tradutor, então, deve levar em consideração não somente $\mathrm{o}$ 
texto verbal presente na obra, mas também o texto não verbal e sua função primordial: comunicar algo, passar uma mensagem.

\section{2) A questão da purificação}

O termo cunhado por Klingber (1986) para assuntos relativos à censura presente na LIJ denomina-se purificação (purification). A purificação na LIJ ocorre quando o texto fonte (TF) é adaptado para o conjunto de valores da cultura alvo. Ela ocorre quando, aos olhos do tradutor e/ou da editora, o TF traz algo inaceitável para a cultura do TA, ou seja, quando o conteúdo do TF vai de encontro à moral e aos bons costumes culturais do público alvo do TA, tocando em temas tabus à determinada cultura (KLINGBERG, 1986).

A purificação tem por intuito deixar o TA de acordo com os valores de seu leitor-alvo - a criança e o jovem. Porém, levar em consideração somente os valores e bons costumes das crianças e jovens não é suficiente para que o texto seja aceito na comunidade a que se destina, uma vez que não são esses leitores quem definem o que é ou não adequado, e sim os responsáveis pela criança / pelo jovem. Com isso, conteúdos e temas purificados na LIJ levam em consideração, acima de tudo, os valores dos responsáveis pela criança: pais, escolas, professores, editoras, críticos, etc.

Klingberg (1986) afirma que a purificação, na maior parte dos casos, é uma tentativa de proteger a criança da realidade quando conteúdos não parecem apropriados à cultura do TA. Os temas tabus para a cultura de chegada e que tendem a ser purificados são, segundo o autor, temas de cunho religioso, político, sexual, entre outros. Por outro lado, "o objetivo de apresentar obras literárias como leitura em sua totalidade e com suas características próprias, assim como o objetivo de promover o panorama internacional e o entendimento dos leitores, irá [...] depor contra a purificação" (KLINGBERG, 1986, p. 58, tradução nossa ${ }^{\text {viii }}$ ).

Klingberg (1986) traz em seu livro Children's Fiction in the Hands of the Translators exemplos de casos de purificação em passagens que mencionam erotismo, escatologia, crianças comportando-se de maneira inadequada e adultos pecadores. A seguir, apresento, então, alguns dos exemplos trazidos pelo autor, bem como um exemplo apresentado por Adriana Silene Vieira (2004), em sua tese de doutorado. Logo após, trago exemplos de purificação ocorridos na HQ Romeu e Julieta, da Turma da Mônica, produzida pela MSP, edição de1997.

\subsection{1) Purificação: erotismo}

No livro do escritor sueco Tove Jansson, Trollkarlenshatt(1948), em inglês intitulado Finn Family Moomintroll (1961) e em alemão intitulado Einedrollige Gesellschaft (1954) (apud KLINGBERG, 1986, p. 59), Klingberg cita o exemplo da 
passagem em que, no TF (sueco), a mocinha dorme com a cabeça no colo do Moomintroll (personagem do livro), que a chama de "minha rosa matinal". No TA para o alemão, ocorre a purificação: a mocinha dorme enrolada em um edredom, ao invés de dormir com a cabeça no colo do personagem, e a passagem sobre a rosa matinal, presente no TF, foi apagada do TA (KLINGBERG, 1986, p. 59).

\subsection{2) Purificação: escatologia}

No mesmo livro supracitado (JANSSON, apud KLINGBERG, 1986, p. 59), há a purificação da escatologia na passagem em que um dos personagens explica aos colegas porque havia saído no meio da noite. No TF, a passagem "Eu só precisei sair para fazer xixi” foi purificada no TA em alemão para "Eu só quis sair um pouco". Já no TA em inglês, temos "Eu só queria olhar as estrelas" (KLINGBERG, 1986, p. 59). Percebe-se, então, que a menção à urina e ao ato de urinar, presente no TF, foi apagada (purificada) de ambas as traduções citadas.

\subsection{3) Purificação: erotismo e escatologia}

Adriana Silene Vieira, em sua tese de doutorado intitulada Viagens de Gulliver ao Brasil - Estudo das Adaptações de Gulliver's Travels por Carlos Jansen e por Monteiro Lobato (2004), traz exemplos de casos de purificação na obra Viagens de Gulliver. Um desses exemplos aborda a purificação de dois temas simultaneamente: erotismo e escatologia.

No TF de Gulliver's Travel, escrito por Jonathan Swift em 1726, Gulliver apaga o fogo que estava destruindo a vila ao urinar sobre ele, havendo, com isso, a menção ao órgão sexual masculino e à urina. No TA por Carlos Jansen em 1888, Gulliver apaga o fogo com seu chapéu gigante, enchendo-o de água suja do esgoto. Já no TA por Monteiro Lobato, em 1937, Gulliver apaga o fogo com seu chapéu gigante, enchendo-o de água, porém água limpa, e não do esgoto. Podemos observar, com isso, que em ambos os TA a menção ao órgão sexual masculino e à urina é purificada. No texto de Jansen, apesar do apagamento do ato de urinar, ainda há menção à água suja de esgoto; e no texto de Lobato a água é limpa, e não poluída.

\subsection{4) Purificação: crianças com comportamentos inadequados}

Segundo Klingberg (1986), a purificação relativa a crianças comportando-se de maneira inadequada geralmente ocorre pelo medo de fazer com que os leitores da LIJ pensem que outras crianças às vezes se comportam de maneira diversa da prescrita pelos adultos.

Na obra Pippi Longstocking, de Astrid Lindgren (apud KLINGBERG, 1986, p. 60), há um trecho em que Pippi, uma das personagens do livro, encontra três armas no 
porão e diz que armas não devem ser utilizadas por crianças. Apesar disso, Pippi dispara duas das armas e pergunta aos seus dois amigos (crianças) se eles gostariam de usar uma arma cada um. As crianças respondem que gostariam. No TA para o alemão, não há tempo para as crianças responderem que gostariam de usar as armas. A tradução coloca palavras na boca de Pippi, que diz: "Well no, I think that we should put them back into the chest. They're not for children!” (KLINGBERG, 1986, p. 60). (Em tradução livre, temos: "Bem, não, eu acho que nós deveríamos colocá-las de volta no cofre. Armas não são para crianças!”).

\title{
4.2.5) Purificação: adultos pecadores
}

Por fim, temos a purificação quando o tema é relativo a adultos pecadores. Em Annelise - tretten ar, de Tove Ditlevseth (apud KLINGBERG, 1986, p. 61), há menção ao uso de álcool e violência à mulher no TF. No TA, ocorre somente a menção ao alcoolismo. Em relação à violência à mulher, ora tais passagens são apagadas, ora são adaptadas, como no trecho em que a mulher aparece com o olho machucado no TF ("The injured eye", em tradução livre "O olho machucado") e no TA temos a adaptação para "The eyes red with weeping" (Em tradução livre, "Os olhos vermelhos de choro") (KLINGBERG, 1986, p. 61).Outros trechos de purificação de LIJ são exemplificados em Klingberg (1986).

Para concluir a seção sobre purificação, trago a citação de Klingberg que discute a necessidade de purificar ou não. O autor afirma que

\begin{abstract}
A purificação ocorre no ponto de intersecção entre os objetivos pedagógicos. Se o objetivo de contribuir para o panorama internacional e para a compreensão dos jovens leitores é levado a sério, visões estrangeiras ideológicas e morais também devem estar presentes no TA. Porém, outro objetivo de publicar literatura infanto-juvenil é colaborar para um desenvolvimento do conjunto de valores do leitor, e nós temos que reconhecer que existem diferenças entre as áreas culturais no que diz respeito a quais valores são vistos como adequados para passar para novas gerações (KLINGBERG, 1986, p. 62, tradução e grifos nossos ${ }^{\mathrm{ix}}$ ).
\end{abstract}

\subsection{6) A purificação na HQ Romeu e Julieta, da Turma da Mônica}

Nesta subseção, trago alguns exemplos de purificação que ocorreram na adaptação do clássico Romeu e Julieta, de William Shakespeare, para a HQ Romeu e Julieta, da Turma da Mônica, reedição de 1997. A tragédia shakespeariana Romeu e Julieta foi adaptada para quadrinhos pela MSP pela primeira vez em 1978, e teve diversas reedições após sua primeira publicação: em 1979, em 1986, em 1993, em 1997, 
em 2000, em 2003, em 2005 e em 2009. O que variou de edição a edição foram as cores utilizadas e, nas reedições feitas pela Editoria Abril, houve também corte de páginas e fusão de alguns capítulos (RIBEIRO \& RODRIGUES, 2009). A edição de 1997 encontra-se disponível no website da Turma da Mônica, sendo, por isso, a edição a qual tive acesso e a que analiso neste artigo.

O enfoque dado é em relação à purificação é a morte dos personagens Romeu e Julieta, que ocorre na tragédia shakespeariana original e não acontece na HQ analisada, uma vez que o principal leitor das HQs da Turma da Mônica é a criança. Ocorre, então, uma suavização no enredo e em seu clímax quando a história é adaptada aos quadrinhos infanto-juvenis.

Na história original, escrita por Shakespeare entre 1591 e 1595, Romeu e Julieta casam-se em segredo, pois suas famílias (a família Montecchio e a família Capuleto) são fortes rivais. Julieta está prometida ao Conde Páris, e, para despistar seus pais, aceita o casamento, com o conselho do Frei Lourenço. O Frei dá a Julieta um elixir para que ela tome e se finja de morta, assim o casamento com o conde não ocorreria. $\mathrm{O}$ Frei enviaria uma carta a Romeu, explicando a situação, e pedindo que voltasse para ficar com Julieta. Mas a carta é extraviada e Romeu não recebe a notícia do que realmente ocorreu. Com isso, passa a acreditar na morte de Julieta. Romeu compra um veneno para tomar e, após assassinar o Conde Páris, que estava no mausoléu com Julieta (que se fingia de morta), toma o veneno e morre ao lado de Julieta. Ao acordar e saber do ocorrido, Julieta tenta absorver o veneno dos lábios de Romeu por meio de um beijo e, como não é bem sucedida, mata-se com a adaga de Romeu (Shakespeare, W. obra completa v.1. Rio de janeiro: Nova Aguilar, 1988).

Na HQ da Turma da Mônica, adaptada ao público infanto-juvenil, Cascão, no papel do Frei, quer ajudar Julieta (interpretada por Mônica) a ficar com Romeu (interpretado por Cebolinha), e, para isso, pesquisa na obra Romeu e Julieta de Shakespeare o que fazer. O que ocorre segue abaixo: 

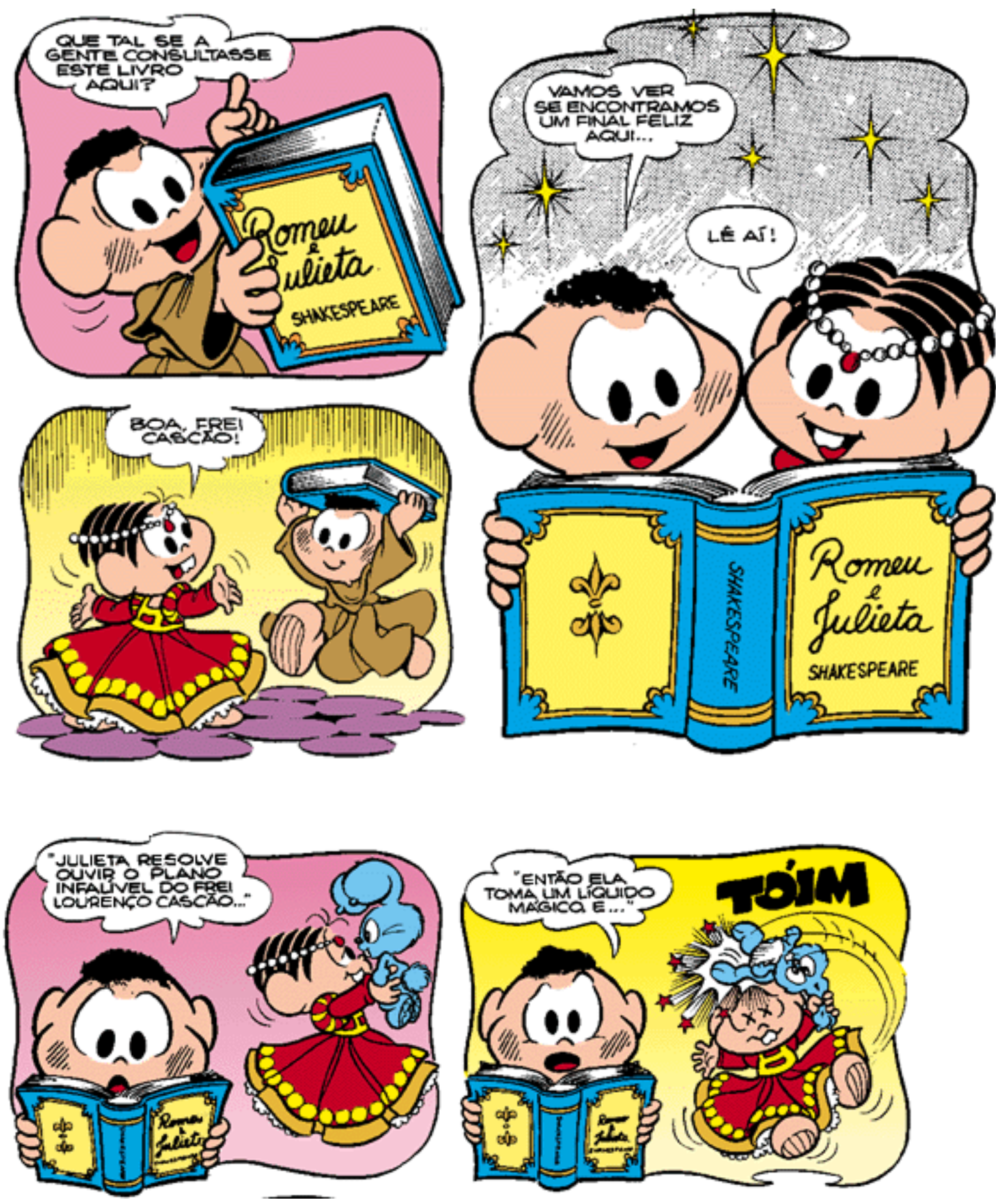

- 1997 MaURicio de sousa PaOduÇOES

Revista Escrita

Rua Marquês de São Vicente, 225 Gávea/RJ CEP 22451-900 Brasil

Ano 2013. Número 17. ISSN 1679-6888.

escrita@puc-rio.br 

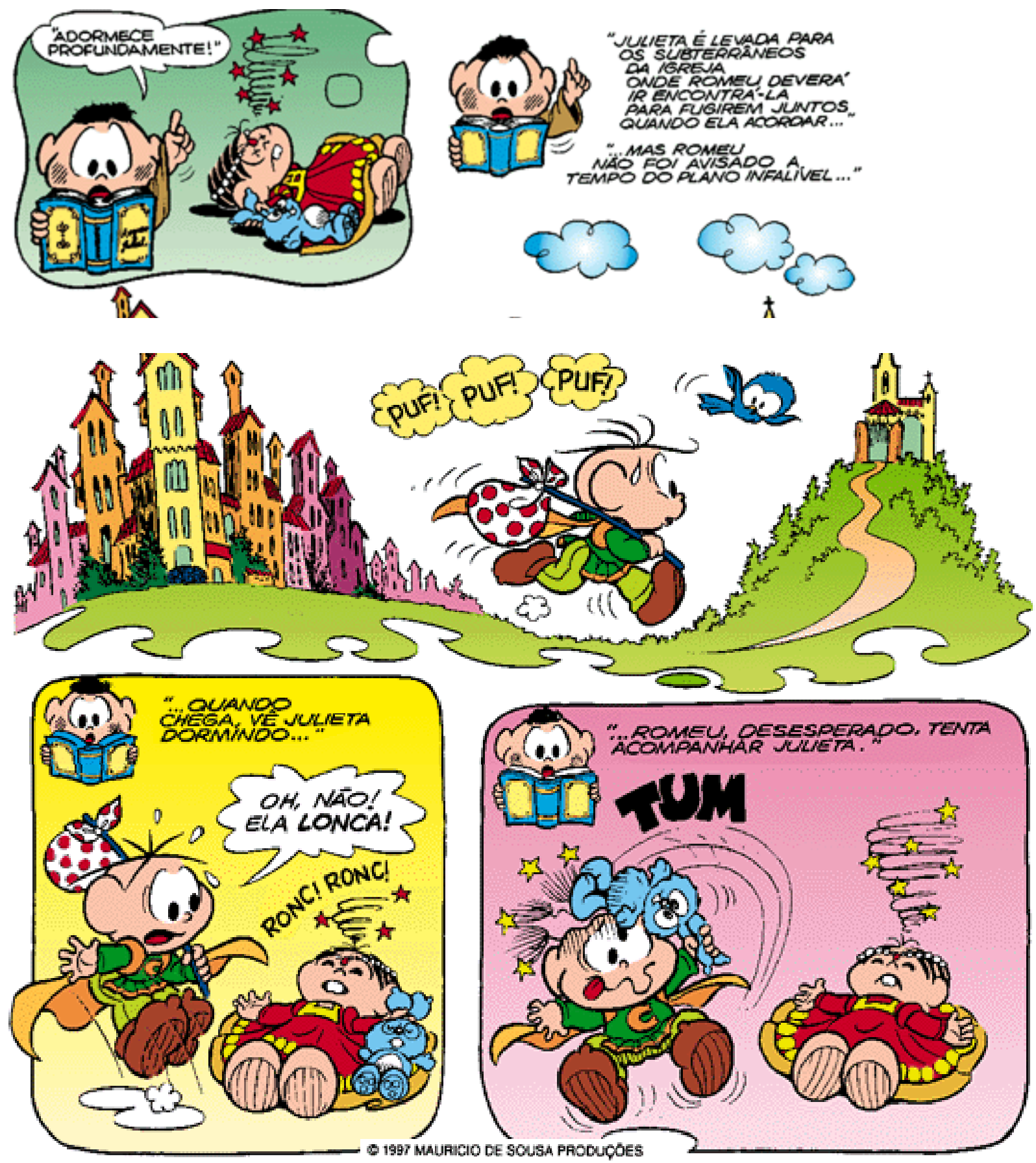

Revista Escrita

Rua Marquês de São Vicente, 225 Gávea/RJ CEP 22451-900 Brasil

Ano 2013. Número 17. ISSN 1679-6888.

escrita@puc-rio.br 

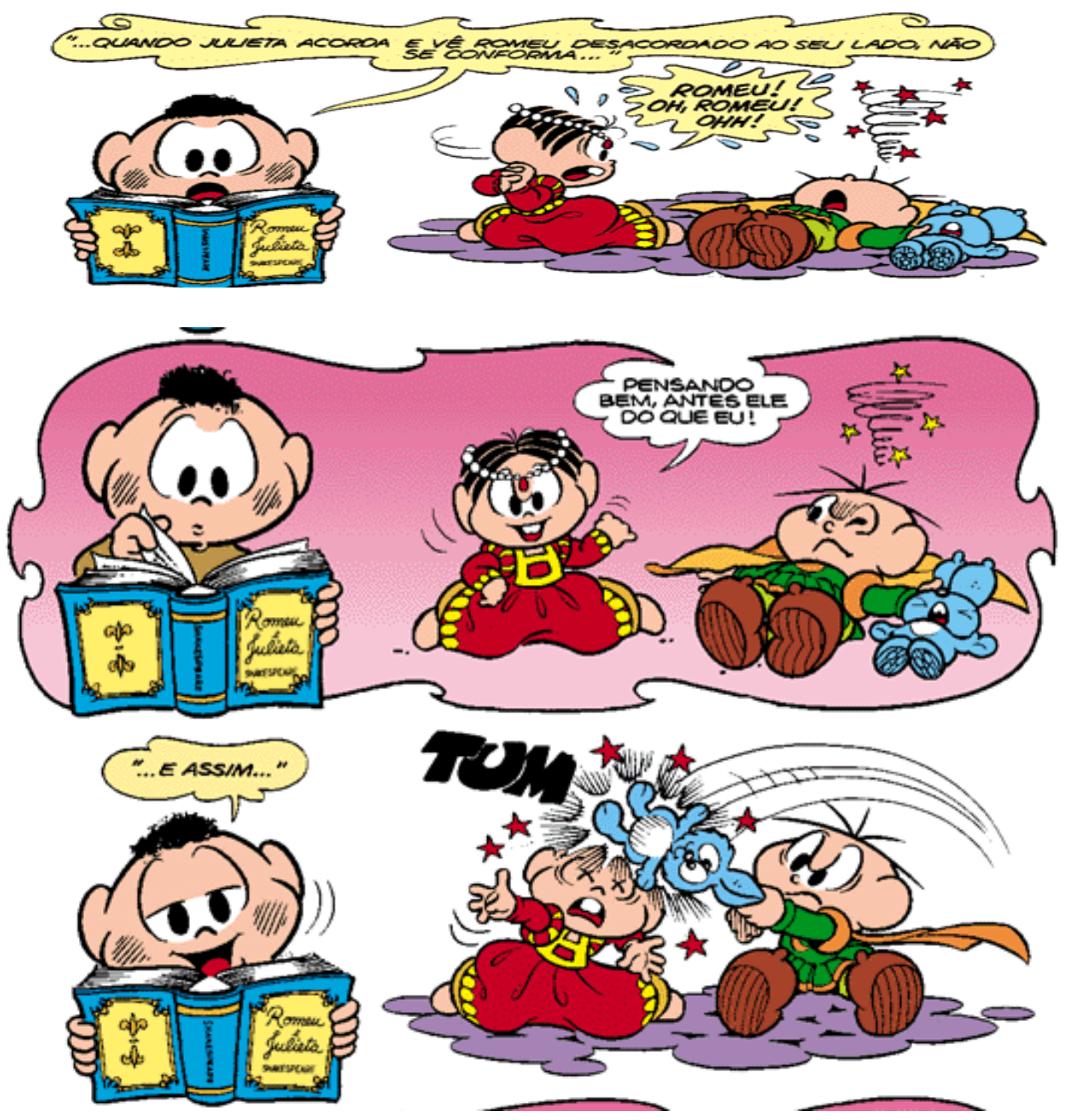

- 1997 MAuRICIO DE SCUSA PROQUÇOES

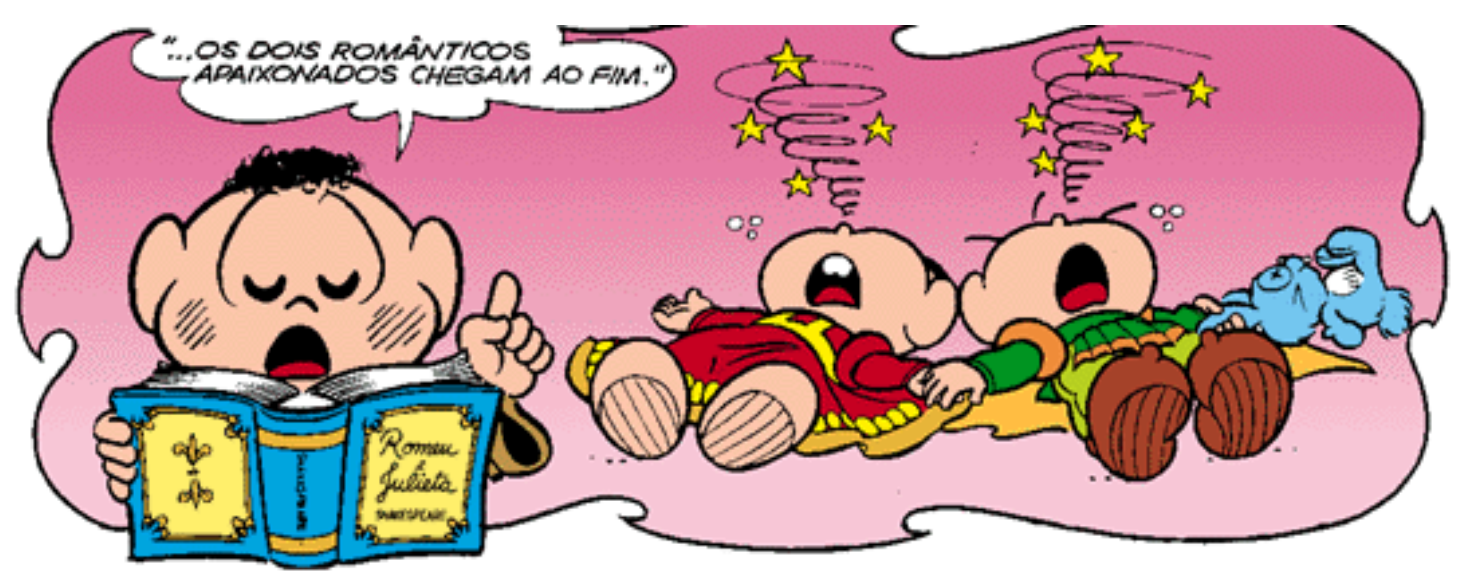

Revista Escrita

Rua Marquês de São Vicente, 225 Gávea/RJ CEP 22451-900 Brasil

Ano 2013. Número 17. ISSN 1679-6888.

escrita@puc-rio.br 


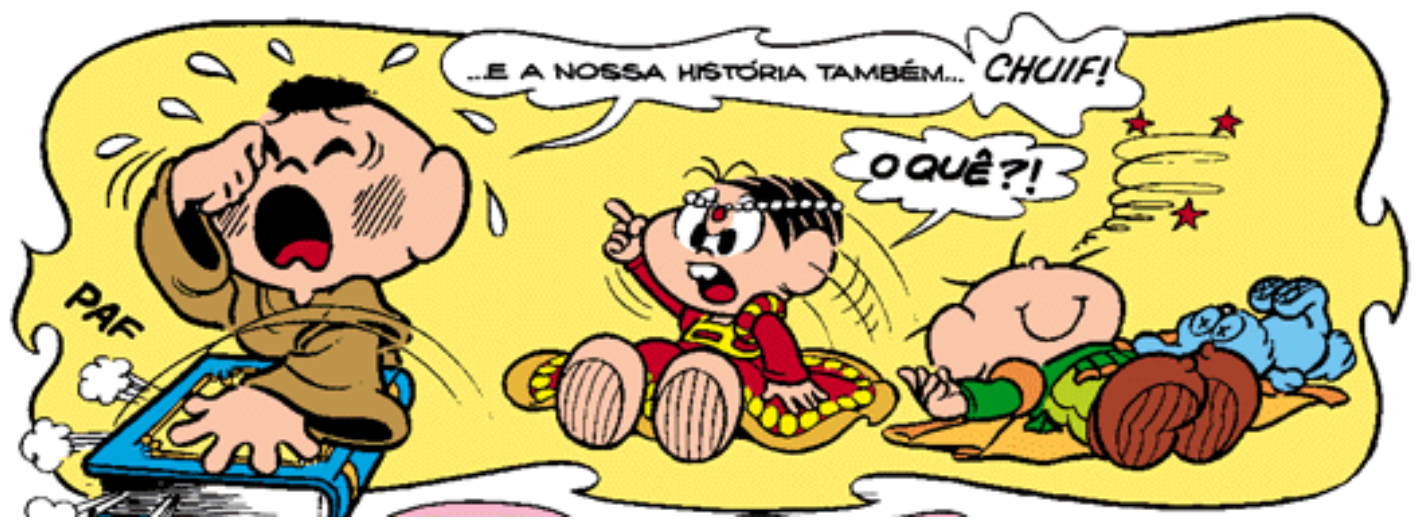

- 1997 MAuRacio de sousa PRoducóes
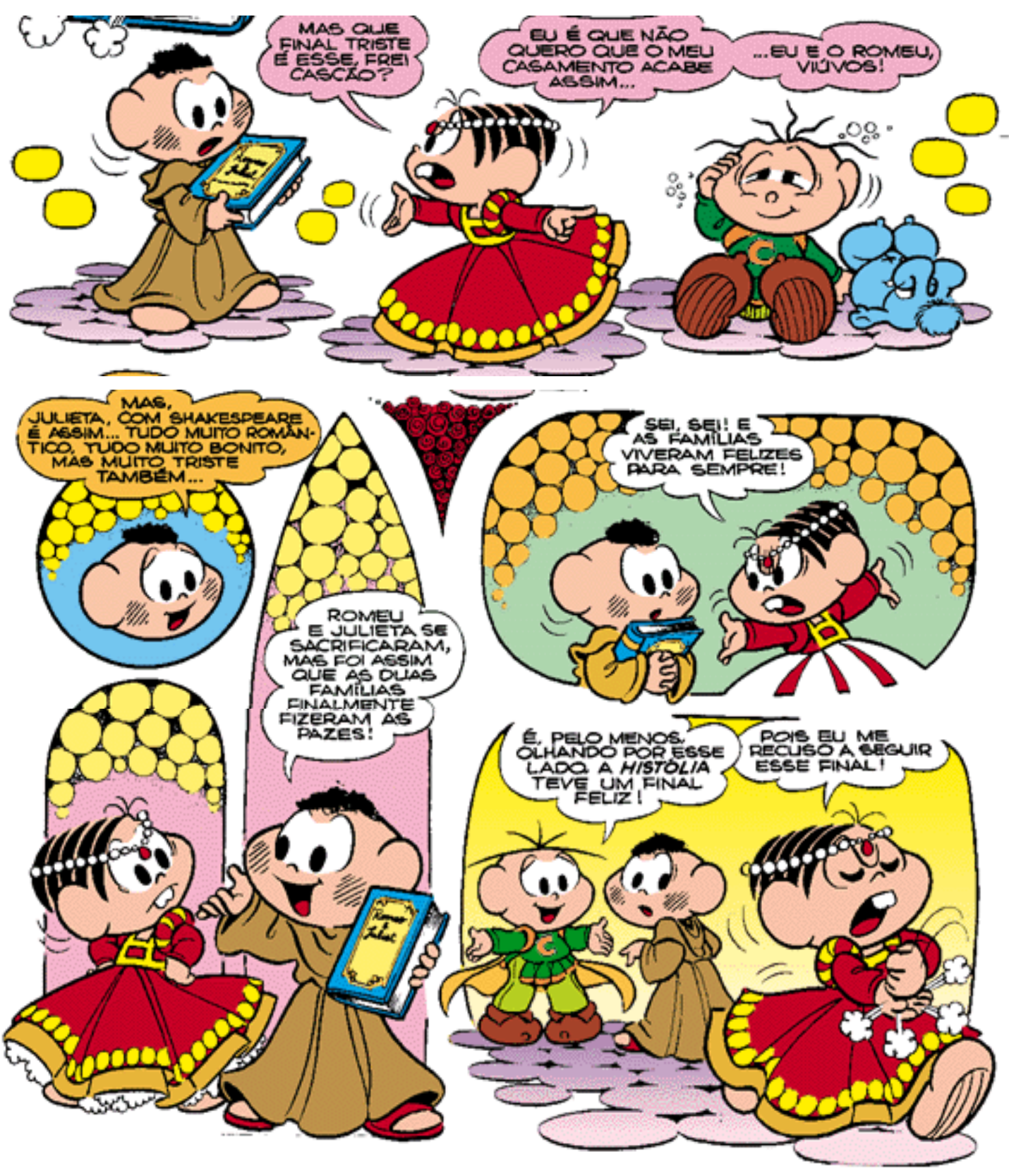

Revista Escrita

Rua Marquês de São Vicente, 225 Gávea/RJ CEP 22451-900 Brasil Ano 2013. Número 17. ISSN 1679-6888. 


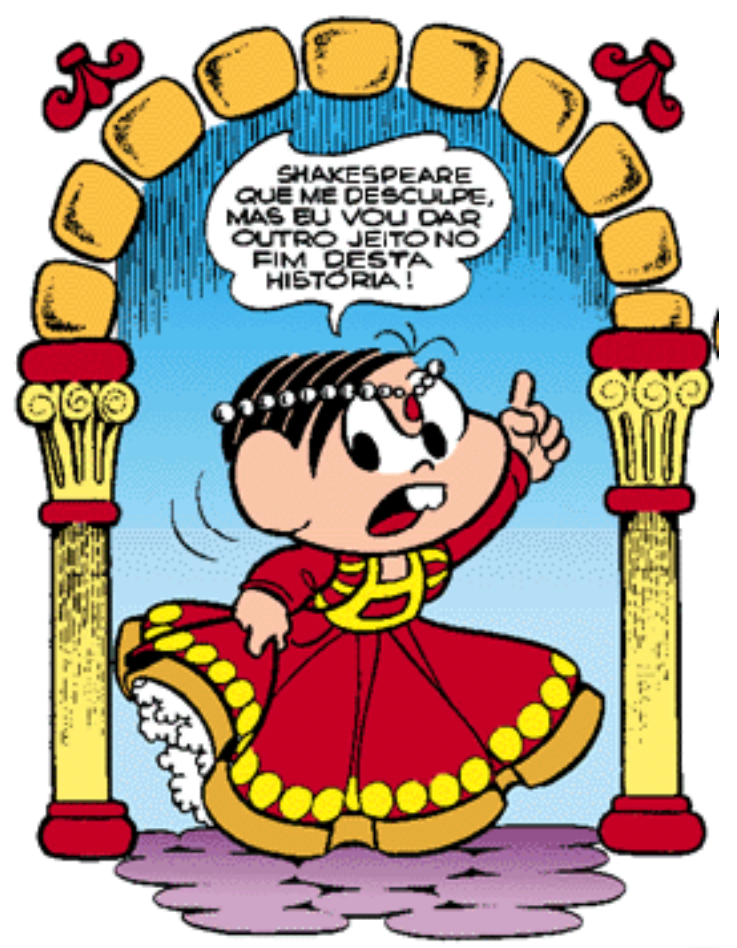

- 1997 MaURICIO de scusa paOduçoes

O que podemos notar a partir do trecho acima mostrado é que o veneno da obra original torna-se um líquido mágico na adaptação da Turma da Mônica, preservando o contato da criança com a palavra veneno e todas as suas implicaturas. Na figura, porém, Julieta nem chega a tomar o tal líquido mágico, e sim desmaia ao se bater com o coelhinho. Em momento algum é dito que Julieta irá forjar sua morte. A morte está fora de questão na HQ. O que se narra é que Julieta dorme profundamente. Romeu vê Julieta dormindo e se desespera, não pelo fato de achar que sua amada está morta, como na obra original, e sim por notar que ela ronca (o drama passa a possuir um caráter cômico na adaptação). Romeu também se bate com o coelho e dorme, mas acorda ao ouvir o que Julieta diz e bate nela com o coelho. Assim, os dois desmaiam.

Na obra Romeu e Julieta mencionada na HQ da Turma da Mônica, o final triste se daria pelo fato de os amados acabarem desacordados (note que nem se usa a palavra desmaiado, e sim, as palavras "adormece", "dormindo", "desacordado"). Não é feita menção à morte nem ao veneno, e, na HQ, o final triste (que seriam os amados desacordados) não ocorre, pois, como Julieta diz no último quadro do trecho 
selecionado, "Shakespeare que me desculpe, mas eu vou dar outro jeito no fim desta história". E assim o faz, casando-se à força com Romeu, para manter a relação cômica existente no fato do Cebolinha não gostar da Mônica nas HQs da turminha. Com isso, notamos que a HQ Romeu e Julieta tem um final feliz e cômico, sendo ela adaptada (purificada) para o público que pretende atingir.

\section{5) Considerações finais}

Diferentemente do que pensa o senso comum, traduzir para criança não é necessariamente mais simples nem menos trabalhoso do que a tradução de outro gênero textual. O contexto de recepção do TA deve sempre ser levado em conta, tanto na tradução de LIJ quanto em qualquer outro tipo de tradução.

O texto não verbal, característica comum da LIJ, não deve ser ignorado na tradução, sendo que os textos verbal e não verbal não podem se contradizer. Como na tradução muitas vezes somente o texto verbal é modificado, ficando o texto não verbal imutável, o tradutor pode passar por complicações em traduções em que o texto conta com texto não verbal, uma vez que figuras e cores não têm significados universais.

Outro ponto limitador na tradução de LIJ é a questão da censura (purificação). Diferentes culturas veem a criança e o jovem de maneira diferente, e entendem o que é adequado e inadequado para esse público de maneira diversa. Alguns exemplos dados neste artigo demonstram que temas tabus para determinada cultura tendem a ser purificados na recepção do texto pela cultura alvo. Além disso, trago um exemplo da análise de um trecho da HQ Romeu e Julieta, da Turma da Mônica, que nos mostra a purificação de um tema considerado tabu para a criança e o jovem: a morte.

\footnotetext{
${ }^{\text {i }}$ In the academic world of today research of children's literature is not really legitimized, it is not highly respected, and if it is at all tolerated it is perceived as a peripheral and insignificant field of research. In short, research of children's literature suffers nowadays from an inferior status. And if nothing is done about it, this will continue for years to come.

ii “[...] a genre written and published, if not exclusively for children, then at least bearing them in mind, including the 'teen' novel, which is aimed at the young and late adolescent readers".

iii Children's literature is generally seen as a peripheral and uninteresting object of study despite the manifold role it plays as an educational, social and ideological instrument. Apart from being entertainment and a tool for developing children's reading skills, it is also an important conveyor of world knowledge, ideas, values, and accepted behaviour. [...] When children's books are translated, it may be necessary to make various adjustments in order to adhere to the notions of what is good and appropriate for children, as well as what is considered the suitable level of difficulty in a given target culture.

${ }^{\text {iv }}$ Segundo o Dictionary of Translation Studies (SHUTTLEWORTH\&COWIE, 1997, p. 127), a teoria dos polissistemas é utilizada para explicar o comportamento e a evolução do sistema literário. O termo
} 
"polissistema" denota um conglomerado estratificado de elementos interconectados, que muda e se transforma à medida que esses elementos interagem uns com os outros. Na teoria dos polissistemas, a obra literária não é estudada de maneira isolada, e sim como parte de um sistema literário. O que ocorre é que um sistema literário pode influenciar outros, e a literatura traduzida importada para um país pode influenciar os escritos nativos (EVEN-ZOHAR, 1978).

v A LIJ (traduzida) inicia a criança no mundo da leitura, podendo formar um leitor autêntico ou um leitor frustrado, sendo essa uma de suas grandes responsabilidades.

vi The belief that there is a kind of visual Esperanto is rooted in the assumption that, unlike arbitrary linguistic signs, pictures exhibit a direct similarity to the reality they represent. However, Eco (1972:202) $[\ldots]$ has demonstrated that pictures have a code which is governed by conventions, and these conventions may by shaped by cultural constraints. This also means that the visual representation of objects, gestures, facial expressions, etc. can be interpreted correctly only if the significance of these elements has been defined in the particular culture (cf. Eco1987:65).

vii A presença de figuras marcantes da cultura do texto fonte pode criar barreiras à interpretação de uma HQ traduzida. É papel do tradutor fazer adaptações para que o leitor do texto alvo entenda a mensagem passada, lembrando-se de que o texto verbal tem de fazer referência às imagens ou complementá-las e que falas e imagens não podem se contradizer (LIBERATTI, 2012).

viii The goal of presenting literary works as reading matter in their totality and with their distinctive characteristics, as well as the goal of furthering the readers' international outlook and understanding, will [...] speak against purification.

ix " [...] purification occurs at the point of intersection between pedagogical goals. If the goal of contributing to the international outlook and understanding of young readers is taken seriously, foreign ideological and moral views should also be presented in the target texts. But another goal of publishing children's literature is to bring about a development of the readers set of values, and we have to acknowledge that there are differences between cultural areas with regard to what values are thought fitting to pass on to the new generation.

\section{Referências bibliográficas}

COELHO, N. N. Dicionário Crítico da Literatura Infantil e Juvenil Brasileira. São Paulo: Nacional, 2006.

CUNHA, M. A. A. Literatura Infantil: Teoria e Prática. São Paulo: Ática, 1994.

EVEN-ZOHAR, I. (1978). "The Position of Translated Literature within the Literary Polysystem". In:Venuti, L. (Ed.).The Translation Studies Reader. London and New York: Routledge, 2000.p. 192-197.

FERNANDES, L. P. Practices of Translating Names in Children's Fantasy Literature: A Corpus-based Study. Tese de doutorado não publicada. Universidade Federal de Santa Catarina, Florianópolis, 2004.

KAINDL, K. (2004). "Multimodality in the translation of humour in comics". In: Charles, C.; Kaltenacher, M.; Ventola, M. Perspectives on Multimodality. John Benjamins B.V., 2004. p. $173-192$. 
KLINGBERG, G. Children's Fiction in the Hands of the Translators. Bloms Boktryckeri, Lund, 1986.

LATHEY, G. (ed.). The Translation of Children's Literature: A Reader. Clevedon: Multilingual Matters, 2006.

LIBERATTI, Elisângela. Ara, Chico; Aw, Chuck: uma tradução funcionalista de quadrinhos do Chico Bento. 2012. 165 p. Dissertação (Mestrado em Estudos da Tradução). Universidade Federal de Santa Catarina. Florianópolis - SC. Disponível em http://www.pget.ufsc.br/curso/dissertacoes/Elisangela_Liberatti_-_Dissertacao.pdf

MEIRELES, C. Problemas da Literatura Infantil. $3^{\text {a }}$. ed. Rio de Janeiro: Nova Fronteira, 1984.

OITTINEN, R. Translating for Children. New York: Garland Publishing, 2000.

PUURTINEN, T. Linguistic Acceptability in Translated Children's Literature. Joensuu: University of Joensuu, 1995.

RIBEIRO, J. R.; RODRIGUES, E. "Romeu e Julieta em edição muito especial". In: Planeta Gibi. 2009. Disponível em: http://www.planetagibi.net/2009/09/romeu-ejulieta-em-edicao-muito.html. Acesso em: 19/07/2013.

SHAVIT, Z. "Beyond the Restrictive Frameworks of the Past: Semiotics of Children's Literature - A New Perspective for the Study of the Field". In Hans-Heino Ewers, Gertrud Lehnert und Emer O'Sullivan (Hrgs.) Kinderliteratur im interkulturellen Prozeß. Studien zur Allgemeinen und Vergleichenden Kinderliteraturwissenschaft, Metzler: Stuttgart, 1994, 3-15. Disponível em: http://www.tau.ac.il/ zshavit/articles/37_Beyond_the_Restrictive.pdf. Acesso em: 10/02/2013.

SHUTTLEWORTH, M. \&COWIE, M. Dictionary of Translation Studies Manchester: St Jerome, 1997.

SOUSA, M. "Halloween na Roça". Disponível em:

<http://www.monica.com.br/comics/halloween/welcome.htm>. Acesso em: 19/07/2013. . "Romeu e Julieta". Disponível em:

<http://www.monica.com.br/comics/rom-juli/welcome.htm>. Acesso em: 19/07/2013.

VERGUEIRO, W. História em quadrinhos em debate. 2009. Disponível em: http://www.revistapontocom.org.br/edicoes-anteriores-conversa-com/historia-emquadrinhos-em-debate. Acesso em: 15/02/2013. 
VIEIRA, A. S. Viagens de Gulliver ao Brasil (Estudo das Adaptações de Gulliver's Travels por Carlos Jansen e por Monteiro Lobato). Campinas: Universidade Estadual de Campinas, 2004. disponível em

http://www.bibliotecadigital.unicamp.br/document/?code=vtls000320939\&fd=y http://www.universohq.com/quadrinhos/2007/n08022007_03.cfm. Acesso em: 14/01/2013.

\section{Referências das figuras:}

Figura 1: disponível em http://www.maxmangas.com.br/naruto/42/2/

Figura 2: disponível em http://www.masquemario.net/htm/tipografia.htm 